\title{
Comparison of radiocarbon and fluorescence based (pump and probe) measurements of phytoplankton photosynthetic characteristics in the Northeast Atlantic Ocean
}

\author{
P. W. Boyd ${ }^{1, *}$, J. Aiken ${ }^{2}$, Z. Kolber ${ }^{3}$

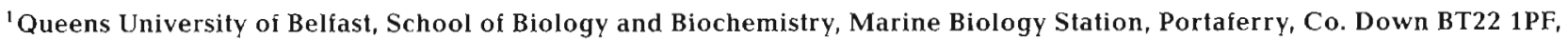 \\ United Kingdom \\ ${ }^{2}$ Plymouth Marine Laboratory, Prospect Place, West Hoe, Plymouth, Devon PL1 3DH, United Kingdom \\ ${ }^{3}$ Oceanographic and Atmospheric Sciences Division, Brookhaven National Laboratory, Upton, New York 11973, USA
}

\begin{abstract}
Significant advances in rapid non-destructive means of measuring the photosynthetic energy conversion of phytoplankton in the ocean have been made in recent years. The new techniques offer the potential to obtain detailed spatial and temporal information about photosynthetic rates that cannot be achieved using more traditional methods. A study of a mesoscale coccolithophore bloom in the Northeast Atlantic enabled the comparison of photosynthetic parameters derived from the Pump and Probe Fluorometer (PPF) and ${ }^{14} \mathrm{C}$ photosynthesis vs irradiance $(P$ vs $I$ ) incubations over a wide varnety of biological, optical and physical conditions. A comparison of the photosynthetic characteristics obtained from the instantaneous PPF and time-integrated ${ }^{14} \mathrm{C}$ approaches demonstrated correlations between parameters, although the absolute values were significantly different. Significant correlations were observed for both $I_{k}$ and $P_{\mathrm{m}}$, while the light-dependent rate constant $\alpha$ was not significant despite a strong correlation between ${ }^{14} \mathrm{C}$-derived $\alpha$ and PPF measurements of the efficiency of photoconversion, $\Delta \phi_{\mathrm{m}}$. The primary reason for the observed discrepancies in the absolute values derived from the 2 approaches were the spectral differences between the artificial light source used for the ${ }^{14} \mathrm{C}$ incubations and the natural underwater light in which the PPF measurements were made. Future studies must consider and correct, via normalization, for such spectral differences. Although the dataset was limited, there was some indication that photoacclimation of the phytoplankton assemblage may have occurred during the $2 \mathrm{~h}^{14} \mathrm{C}$ incubations that took place late in the day. The use of the PPF approach is promising with regard to extending the measurement of photosynthetic characteristics on to the temporal and spatial scales required for the development of more robust bio-optical models and to complement currently avaiłable in situ measurement rates of physical and chemical parameters.
\end{abstract}

KEY WORDS: Photosynthetic characteristics - Intercomparison Active fluorescence - Radiotracer methods Photoacclimation

\section{INTRODUCTION}

Since the 1950s, primary production has been estimated by the incorporation of radioactive ${ }^{14} \mathrm{C}$ by aquatic plants during photosynthesis under in situ conditions in a wide range of marine ecosystems (Peterson

\footnotetext{
- Present address: NIWA Centre for Chemical and Physical Oceanography, Department of Chemistry, University of Otago, Dunedin, New Zealand.E-mail: pboyd@alkali.otago.ac.nz
}

1980). In addition, the ${ }^{14} \mathrm{C}$ technique has been used widely in laboratory and field studies to determine the photosynthetic characteristics of algal cultures and natural phytoplankton populations, and their responses to various conditions of nutrient, temperature and light stress and adaptation (Lewis et al. 1984. Sakshaug \& Holm-Hansen 1986, Cullen \& Lewis 1988). The basic $P_{\text {vs }} I$ characteristics $\left(P_{\mathrm{m}}, \alpha\right.$, and $I_{k}$ : see Table 1) are regarded as measures of the photosynthetic competence and adaptive state of a phytoplankton 
Table 1. Notation for biophysical terms used in the text

\begin{tabular}{|c|c|}
\hline PS2 & Photosystem 2 \\
\hline$P_{\mathrm{m}}$ & $\begin{array}{l}\text { Maximum photosynthetic rate at light } \\
\text { saturation }\end{array}$ \\
\hline$\alpha$ & $\begin{array}{l}\text { Initial slope of the } P \text { vs } I \text { curve; light- } \\
\text { dependent rate constant }\end{array}$ \\
\hline$I_{k}$ & $\begin{array}{l}\text { Light saturation constant; intercept } \\
\text { corresponding to } P_{n 1} / \alpha\end{array}$ \\
\hline$\Delta \phi_{\mathrm{m}}$ & $\begin{array}{l}\text { Maximum change in the quantum yield of } \\
\text { fluorescence }\end{array}$ \\
\hline$\sigma_{p s 2}$ & Functional absorption of cross-section of PS2 \\
\hline$n_{\mathrm{p}<2}$ & Ratıo of PS2 reaction centres to chlorophyll \\
\hline$\tau_{\mathrm{p}}$ & $\begin{array}{l}\text { Minimum turnover time for steady-state } \\
\text { photosynthesis }\end{array}$ \\
\hline$\phi_{\mathrm{e}}$ & $\begin{array}{l}\text { Actual quantum yield of electron transport, } \\
\text { accounting for losses due to the thermal } \\
\text { dissipation and electron cycling around PS2 }\end{array}$ \\
\hline$q_{\mathrm{p}}$ & $\begin{array}{l}\text { Photochemical quenching, a measure of the } \\
\text { fraction of open reaction centres under } \\
\text { ambient photon fluence rates }\end{array}$ \\
\hline$F_{0}, F_{\mathrm{m}}$ & $\begin{array}{l}\text { In wivo fluorescence yield induced by a weak } \\
\text { probe flash in the dark (initial), and following } \\
\text { a saturating flash (maximal), measured in } \\
\text { dark-adapted state where non-photochemical } \\
\text { quenching is at a minimum }\end{array}$ \\
\hline$F_{\mathrm{n}}^{\prime}, F^{\prime}, F_{\mathrm{m}}^{\prime}$ & $\begin{array}{l}\text { In vivo fluorescence yield induced by a weak } \\
\text { probe flash in the dark, under ambient light } \\
\text { and following a saturating flash, all measured } \\
\text { in light-adapted state }\end{array}$ \\
\hline$F_{\mathrm{v}}, F_{v}^{\prime}$ & $\begin{array}{l}\text { Variable fluorescence, difference between the } \\
\text { max and min fluorescence yield measured in } \\
\text { a dark-adapted and light-adapted state }\end{array}$ \\
\hline
\end{tabular}

assemblage. The ${ }^{14} \mathrm{C}$ technique has provided oceanographers with the means of estimating oceanic primary production locally, regionally and globally. However, the method is viewed as an imperfect tool, due to physiological stress on phytoplankton during sampling, manipulation and enclosure (Eppley 1980), the time-consuming nature of the technique, and uncertainties about what photosynthetic processes are being measured (Williams 1993)

For decades, terrestrial biologists (see Govingee 1975) have exploited the fluorescence from photosystem II at $683 \mathrm{~nm}$ as a probe for photosynthetic energetics, reactions and rates, yet these techniques have been used relatively little by aquatic biologists until recently. Pioneering work by Mauzerall (1972) and Ley \& Mauzerall (1982) has been carried forward by Falkowski et al. (1986) leading to the development of pump and probe fluorometry (PPF) and fast repetition rate fluorometric (FRRF) techniques and measurement protocols (Kolber \& Falkowski 1992). Laboratory measurements have been made of the photosynthetic competence, capacity and adaptive state of algae grown under light or nutrient stress (Falkowski et al. 1988 , 1991, Kolber et al. 1988).

The majority of field studies with the PPF (such as Kolber et al. 1990) have revealed a strong relationship between $\Delta \phi_{\mathrm{n}}$ (see Table 1) and environmental parameters such as temperature and dissolved inorganic nitrogen concentration in the ocean. Geider et al. (1993) assessed PPF measurements of maximum quantum efficiency of photosynthesis in the western North Atlantic from offshore (Sargasso Sea) to inshore (Delaware Bay) observing variations in this parameter in 3 oceanographic provinces of differing nutrient status. Recently, Olaizola et al. (1996) provided a synoptic study of this parameter across the North Atlantic and were able to identify the importance of nutrient supply in limiting production over large parts of the transect. Fewer studies have attempted to relate conventional $\left({ }^{14} \mathrm{C}\right)$ and fluorescence-based measurements of primary production. In a paper ostensibly dealing with measurements of nutrient enrichment and enhanced productivity as a result of 'eddy pumping', Falkowski et al. (1991) showed a strong correlation between fluorescence-based productivity estimates and concurrent radiocarbon-based production (using an on-deck incubator) for 21 stations from the Northwest Atlantic and the sub-tropical Pacific, suggesting that the PPF technique may be used to estimate photosynthesis in situ. While other laboratory studies have successfully predicted photosynthetic parameters, such as $I_{k}$, from fluorescence-based measurements using phytoplankton cultures (Kroon et al. 1993), no rigorous comparison of fluorescence-derived and ${ }^{14} \mathrm{C}$ estimates of photosynthetic parameters has been attempted so far during field studies (Kolber \& Falkowski 1993).

Models that predict global primary productivity based on chlorophyll and irradiance are often inaccurate (Balch et al. 1992) and are not yet able to take account of the natural variability in photosynthetic parameters (Kolber \& Falkowski 1993). Balch et al. (1992) suggest that production algorithms may be made more accurate by the inclusion of at least one photoadaptive parameter, and Platt \& Sathyendranath (1993) have discussed the need to resolve better the question of scale with respect to remotely sensed and shipboard-collected data. Such requirements may be met by the development of techniques to rapidly assess the photosynthetic characteristics of the phytoplanktonic assemblage (Sathyendranath et al. 1995). The recent development of a submersible FRRF (Kolber \& Falkowski 1992) has extended the range and sensitivity of fluorescence measurements permitting a larger number of photosynthetic parameters to be measured in situ, including $P_{\mathrm{m}}, I_{k}, \alpha, \sigma_{\mathrm{PS} 2}$ and $\tau_{\mathrm{p}}$ (see Table 1 ). It is in this context that PPF, FRRF and ${ }^{14} \mathrm{C}$ methods converge, allowing comparison of these methods. 
In this paper the results of field studies are presented where measurements of photosynthetic parameters $\left(P_{m}, I_{k}, \alpha\right)$ by PPF and radiocarbon incorporation were taken quasi concurrently to allow comparison.

\section{METHODS AND MATERIALS}

Study area. The comparison of these techniques was carried out, at 16 stations (Fig. 1), during a cruise to study the biogeochemistry of coccolithophorids in the NE Atlantic in June 1991 (see Holligan et al. 1993).

Sampling. Samples for primary production experiments using radiocarbon-based measurements were obtained using clean techniques (Fitzwater et al. 1982), and manipulated, inoculated with ${ }^{14} \mathrm{C}$ and analysed following the procedures described in Joint et al (1993). In order to assess the photosynthetic characteristics of the phytoplankton, experiments were carried out using an artificial light gradient incubator (Joint \& Pomroy 1986). As the PPF technique provides mea. surements which are both instantaneous and provide estimates of gross primary production, the ${ }^{14} \mathrm{C}$ incubations were of short duration ( $2 \mathrm{~h}$ ), in order to approximate gross primary production (Laws 1990) and minimize any diel effects. The incubator design enabled photosynthetic parameters to be estimated using 24 irradiances over an ecologically relevant range for this region $\left(3 \mu \mathrm{mol}\right.$ quanta $\mathrm{m}^{-2} \mathrm{~s}^{-1}$ to $>1500 \mu \mathrm{mol}$ quanta $\mathrm{m}^{-2} \mathrm{~s}^{-1}$ ). The $P$ vs $I$ incubations were initiated within

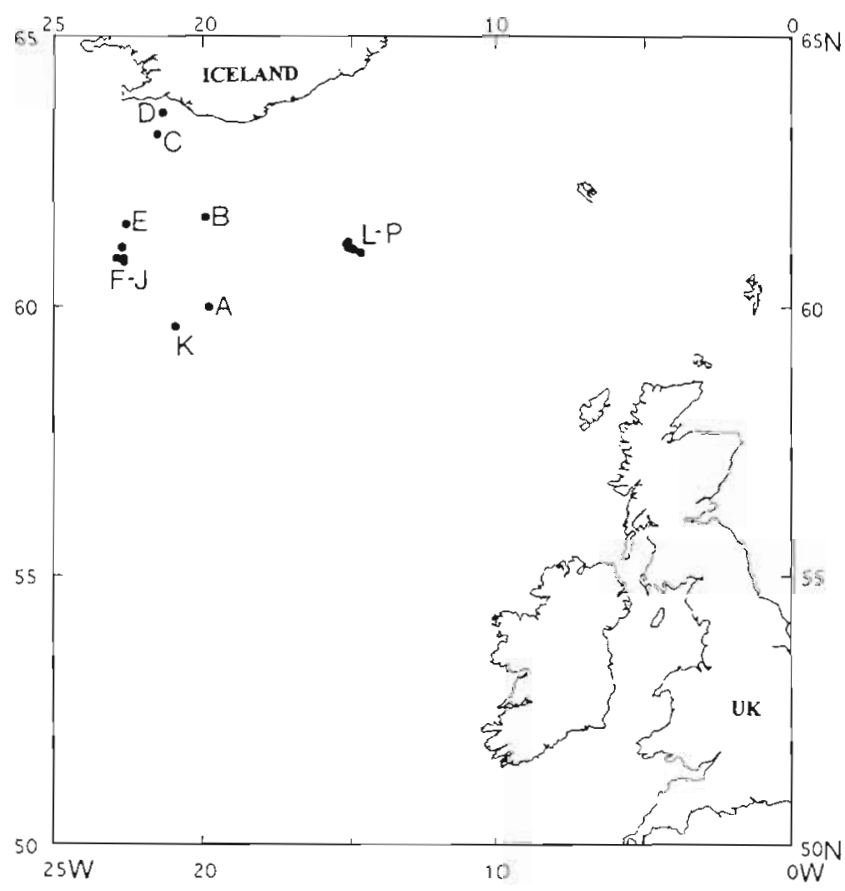

Fig. 1. Map of the study area showing locations of the stations (A to P) at which intercomparisons were performed
15 min of water samples coming on board. Chlorophyll a was analysed by in vitro fluorometry (Parsons et al. 1984)

The PPF used in this study was the instrument described by Kolber et al. (1990) on loan from the Oceanographic and Atmospheric Sciences Division, Brookhaven National Laboratory. Definition of parameters and notation are presented in Table 1 ; data processing and methods of analysis were as described by Kolber \& Falkowski (1993) with minor differences, since only the submersible fluorometer was used; the symbol $I$ for irradiance (PAR) rather than $E$ is used in order to maintain the convention for the photosynthetic parameter $I_{k}$. The PPF was attached to an extreme corner of the rectangular protective frame carrying a CTD and water bottle rosette, thus minimising any shading of the fluorometer by these attachments, and deployed with the ship starboard beam to the sun, to minimize ship shadow effects. PAR (400 to $700 \mathrm{~nm}$ ) was measured in situ on each cast by a hemispherical sensor (Aiken \& Bellan 1986) fixed to the highest point of the CTD frame, pre-calibrated against laboratory irradiance standards and cross-checked throughout the cruise, against the top-side, incident solar PAR sensors (port and starboard) of identical design. The PPF measurements were recorded on the CTD upcast, ensuring adequate flushing of the upward facing sample cuvette; water for the ${ }^{14} \mathrm{C}$-derived $P$ vs $I$ incubations and for fluorometric analysis of chlorophyll a was sampled from the same upcast, at either 7,5 , or $2 \mathrm{~m}$ near the conclusion of the cast. Dark-adapted PPF signal measurements (to calculate $\Delta \phi_{m}$ ) were made at the conclusion of each cast, using samples from the water bottles (discrete depths typically 2, 5, 7, 10, 20, $30 \mathrm{~m}$ ); the PPF cuvette was flushed and filled with water directly from each water bottle and the cells maintained in darkness until stable values were obtained (dark adaptation time of 30 to $120 \mathrm{~s}$ ).

Calculation of photosynthetic parameters. The $P$ vs $I$ data obtained from the ${ }^{14} \mathrm{C}$ experiments were fitted to a model of the $P$ vs $I$ curve based on the mathematical formulation of Smith (1936) using the fitting routine of Lederman \& Tett (1981). The photosynthetic characteristics derived using this approach were assumed to be representative of the phytoplankton assemblage within the surface mixed layer.

The PPF measures the fluorescence signal $\left(F^{\prime}\right)$ from a phytoplankton assemblage in situ generated by a lowintensity 'probe' pulse preceding a high intensity 'pump' pulse which saturates photosystem 2 (PS2); and the signal $\left(F_{\mathrm{m}}^{\prime}\right)$ from a second 'probe' pulse delayed 60 to $100 \mu$ s after the 'pump' when PS2 is totally saturated. Corresponding measurements in the dark (darkadapted state) give $F_{0}$ and $F_{\mathrm{m}}$. From these measurements, the variable fluorescence $\left(F_{\mathrm{v}}=F_{\mathrm{m}}-F_{0}\right)$ and $\left(F_{\mathrm{v}}^{\prime}\right.$ 
$=F_{\mathrm{m}}^{\prime}-F^{\prime}$ ), the maximum change of quantum yield of fluorescence $\Delta \phi_{m}$ and photochemical quenching $q_{p}$ are calculated (for further details see Kolber \& Falkowski 1993).

In situ PPF photosynthetic measurements were derived directly for $I_{k}$ and $P_{m}$, and for $\alpha$ and $\Delta \phi_{m}$, by indirect means; henceforth the parameters derived from PPF measurements are denoted by the subscript 'f', e.g. $I_{k i}, P_{\mathrm{mf}}, \alpha_{\mathrm{f}}$, to differentiate these from the ${ }^{14} \mathrm{C}$ measurements. Examples of the derived parameters $\Delta \phi, \Delta \phi_{\mathrm{m}}\left(=\Delta \phi_{\text {dark }}\right)$, productivity $\left(P_{\mathrm{f}}\right)$ and measured PAR are shown in Fig. 2; data are in $1 \mathrm{~m}$ binned averages except for $\Delta \phi_{\mathrm{m}}$, which has been fitted to the $\Delta \phi_{\mathrm{m}}$ discrete measurements and interpolated (cubic spline). Measurements of $\Delta \phi$ are characteristically low near the surface (photo-inhibited or light saturated regime) and increase with depth until a constant value is reached for depths (>10 m to $15 \mathrm{~m}$ ) where photosynthesis is linearly related to incident PAR (Fig. 2). The inflection point on the curve, or more accurately the point of divergence between $\Delta \phi$ and $\Delta \phi_{\mathrm{m}}$ (as indicated by the horizontal arrow in Fig. 2), gives the depth of light saturation with an uncertainty of $\pm 1 \mathrm{~m}$; the value of PAR at this depth gives the value of the light saturation parameter $I_{k \mathrm{f}}$.

Productivity $\left(P_{\mathrm{f}}\right)$ was calculated following the approach of Kolber \& Falkowski (1993) using:

$$
P_{\mathrm{f}}(z)=I(z) \cdot \sigma_{\mathrm{ps} 2} \cdot q_{\mathrm{p}}(z) \cdot \phi_{\mathrm{e}}(z) \cdot f \cdot n_{\mathrm{ps} 2}
$$

$q_{\mathrm{P}}(z)$ was estimated as

$$
q_{\mathrm{p}}(z) \approx \Delta \phi / \Delta \phi_{\mathrm{m}}=\left(F_{\mathrm{m}}^{\prime}-F^{\prime}\right) /\left(F_{\mathrm{m}}-F_{0}\right)
$$

$\sigma_{\mathrm{ps} 2}$ was assumed to be $400 \AA^{2}$ quanta $^{-1}\left(=4 \times 10^{-18}\right.$ $\mathrm{m}^{2}$ quanta $\left.^{-1}\right) . q_{\mathrm{p}}(z)$, the photochemical quenching, should be expressed as $\left(F_{m}^{\prime}-F^{\prime}\right) /\left(F_{m}^{\prime}-F_{0}^{\prime}\right)$; however the $F_{0}$ signal was not measured upon drawing the sample from the water bottle. This may have resulted in some relaxation of the non-photochemical quenching, leading to a 10 to $20 \%$ underestimate of $q_{\mathrm{p}}$ (Falkowski $\&$ Kolber 1995). $\phi_{\mathrm{e}}(z)$ was assumed to be 0.25 in the linear range of the $P$ vs $I$ curve, where

$$
I(z) \cdot \sigma_{\mathrm{ps} 2} \cdot q_{\mathrm{p}}(z)<1 / \tau_{\mathrm{p}}
$$

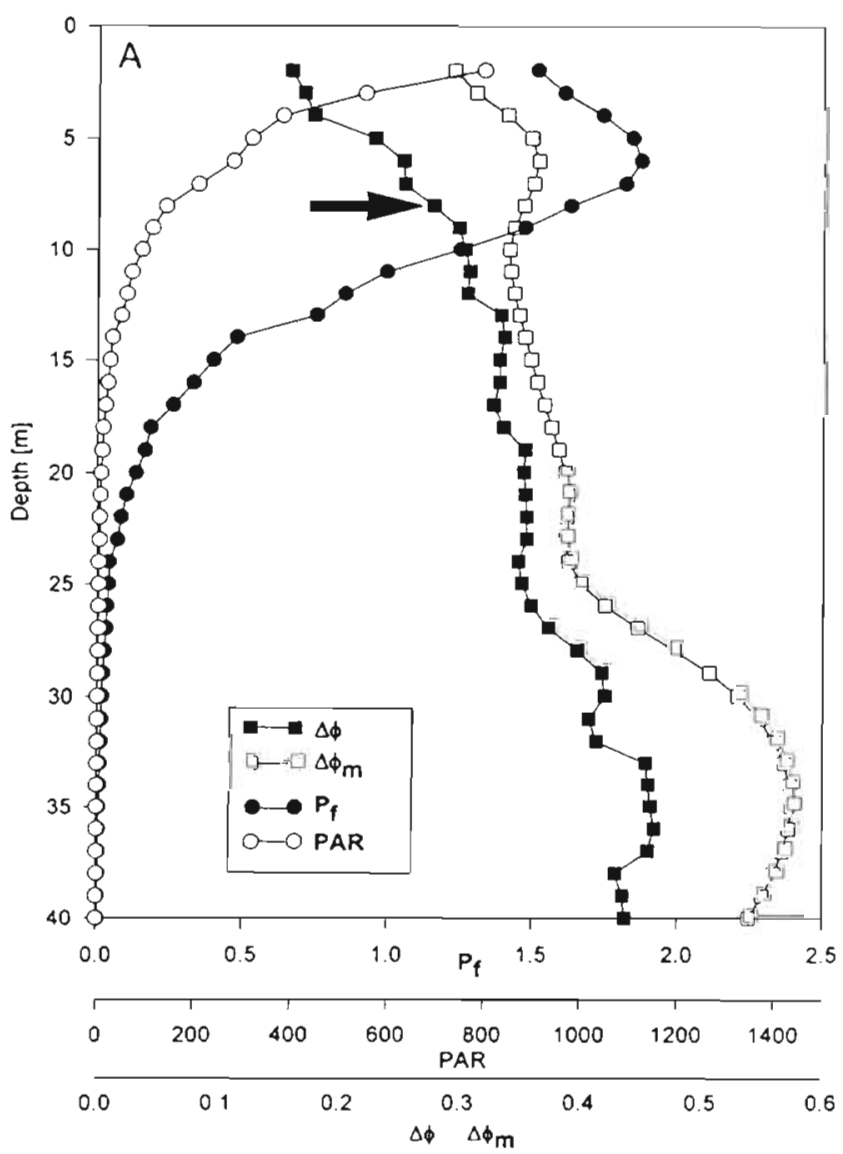

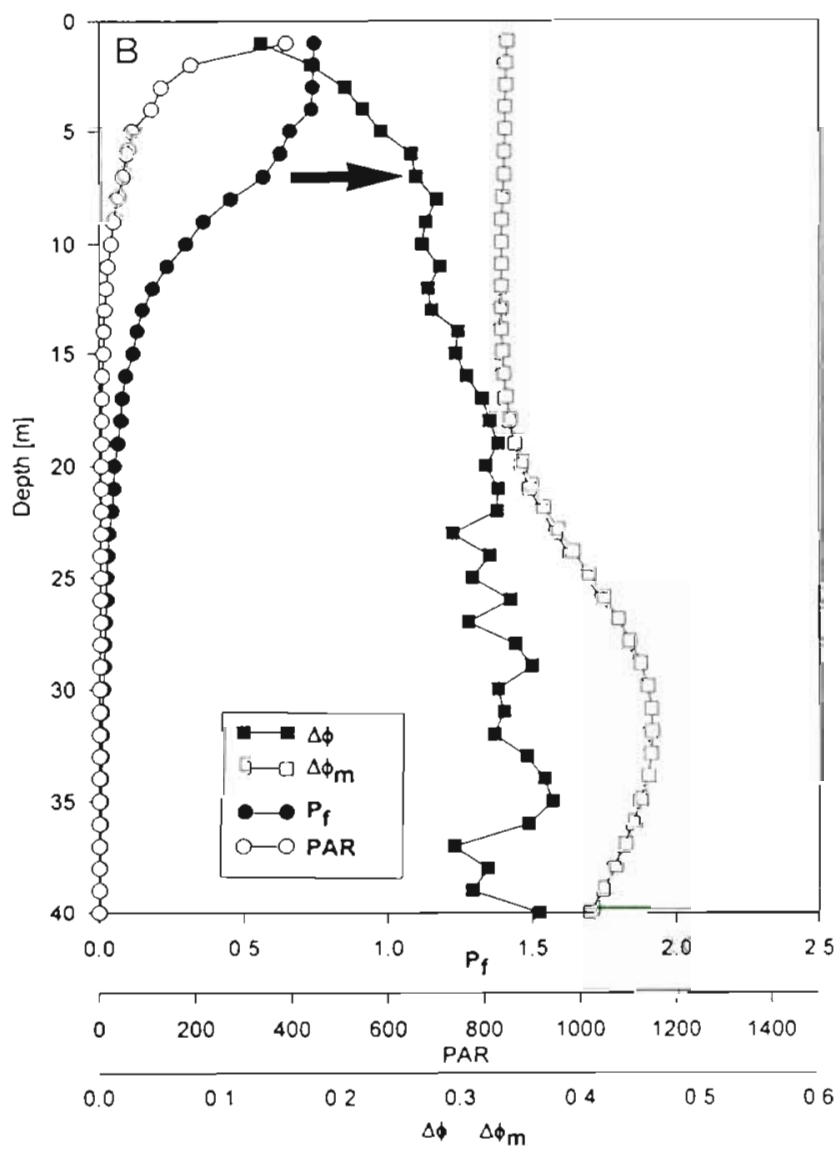

Fig. 2. Representative vertical profiles of PPF measurements for (A) a high light (Stn A), and (B) a low-light station (L). Profiles are of (i) $\Delta \phi$ calculated from $F_{m}^{\prime}$ and $F^{\prime}$, (ii) $\Delta \phi_{m}$ calculated from measurements of discrete water samples from each cast, (iii) calculated production $\left(P_{1}\right)$ from $\Delta \phi$ and $E(z)$ and (iv) observed PAR ( $\mu$ mol quanta $\mathrm{m}^{2} s^{-1}$ ). The horizontal arrow indicates the estimated depth of $I_{k}$ where $\Delta \phi$ and $\Delta \phi_{\mathrm{m}}$ diverge. (The units for $P_{\mathrm{f}}$ are mol electrons chl ${ }^{-1}$ time $^{-1}$ ) 

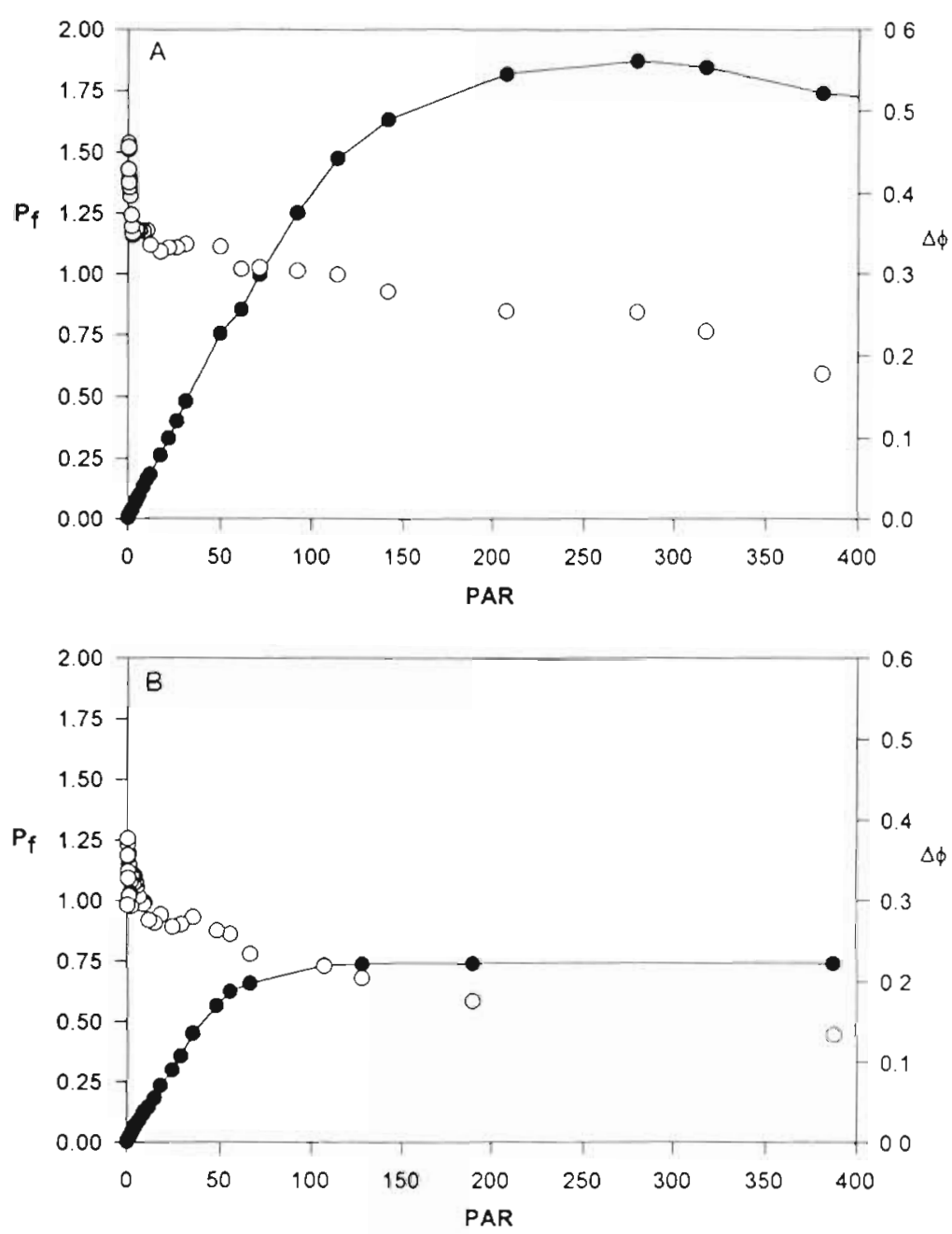

Fig. 3. Calculated primary production $\left(P_{t}\right)$ vs $\operatorname{PAR}\left(\mu \mathrm{mol}\right.$ quanta $\mathrm{m}^{-2} \mathrm{~s}^{-1}$ ) and $\Delta \phi$ vs PAR (O) for (A) Stn A and (B) Stn L. (The units for $P_{\mathrm{f}}$ are mol electrons chl ${ }^{-1}$ time $^{-1}$ )
The photosynthetic rate constant, $\alpha_{f}$, was assessed from the slope of the linear part of the $P$ vs $I$ curves derived from the PPF (Fig. 3). These low-light regime data generally correspond to depths below $15 \mathrm{~m}$, considerably deeper than the water used for ${ }^{14} \mathrm{C}$ measurements at either 7,5 , or $2 \mathrm{~m}$ in a higher light regime. Values of $\Delta \phi_{\mathrm{m}}$ obtained at shallower depths corresponding to water sampling depths for the ${ }^{14} \mathrm{C}$ method are a better, though not exact, representation of photosynthetic rates at these depths. The radiocarbon-derived parameters were normalised to chlorophyll a data to permit direct comparison with the PPF approach (Eq. 1). Fluorescence-based estimates of phytoplankton photosynthesis were converted to carbonbased estimates using Eq. (13) in Kolber \& Falkowski (1993). As fluorescence-based methods count electrons, the photosynthetic quotient (PQ) used in this conversion was assumed to be 1.2 (Kolber \& Falkowski 1993). While greater than 2fold variations in this factor have been observed in field studies of up to $24 \mathrm{~h}$ duration (see review in Geider \& Osborne 1992), the use of short-term radiocarbon incubations minimised in vitro respiratory losses of carbon (Kiefer \& Reynolds 1992) and thus the differences between these 2 approaches were probably minimal (see 'Discussion').

\section{RESULTS}

and calculated as

$$
\phi_{c}=0.25 / l(z) \cdot \sigma_{\mathrm{ps} 2} \cdot q_{\mathrm{p}}(z) \cdot \tau_{\mathrm{p}}
$$

at irradiances exceeding $I_{k}$ (Kolber \& Falkowski 1993), where $\tau_{p}$ (see Table 1) was calculated using the value of $I_{k i}$ (in quanta $\mathrm{m}^{2} \mathrm{~s}^{-1}$ ) from each upcast and $\sigma_{p 52}$. The fraction of reaction centres, $f$, was calculated as

$$
f=1 / 0.65 \cdot\left(F_{\mathrm{m}}-F_{0}\right) / F_{\mathrm{m}}
$$

and $n_{\text {ps2 }}$ was assumed to be 0.00125 . Values of $P_{\mathrm{f}}$ are usually greatest $\left(P_{\mathrm{mf}}\right)$ at depths slightly shallower than the depth of $I_{k}$ and sometimes exhibit photoinhibition. Representative PPF productivity vs PAR $\left(P_{\mathrm{f}}\right.$ vs $\left.I\right)$ curves are shown in Fig. 3 , and resemble the $P$ vs $I$ curves using ${ }^{14} \mathrm{C}$ incubator methods. Since $I_{k !}$ is a quasi-independent measurement, the product of $\alpha_{1}$ and $I_{k f}$ provides an alternative method of calculation of $P_{m i}$ for comparison with the ${ }^{14} \mathrm{C}$ measurements of $P_{\mathrm{m}}$.
Throughout the cruise there were 16 'co-incident' deployments of the PPF and short-term ${ }^{14} \mathrm{C} P$ vs $I$ incubations (Table 2). Values of the photosynthetic parameters $I_{k}, P_{\mathrm{m}}$ and $\alpha$ or $\Delta \phi_{\mathrm{m}}$ were obtained over a wide range of conditions; ambient irradiances at the time of sampling and chlorophyll a showed $>10$-fold and $>3$-fold variations, respectively, in the period between June 19 and 30 (Table 2). The attenuation coefficient of the upper water column, $K_{d}$, varied from 0.120 to $0.227 \mathrm{~m}^{-1}$ over the course of the cruise (Table 2).

\section{Relationship between the two approaches}

Values obtained for $I_{k \mathrm{f}}$ and $I_{k}$ showed a significant linear relationship (Fig. 4A.) with ca $40 \%$ of the variance explained by the regression (Table 3 ). The slope of the regression line (ca 0.28 ) indicated that there was 
Table 2. Sampling times, station positions and biological and physical data measured at time of sampling. $K_{d}$ denotes attenuation coefficient (based on underwater PAR profiles); Photoinhib. denotes evidence of photoinhibition and was estimated from $P$ vs $I$ curves for both approaches $\left(Y={ }^{14} \mathrm{C}_{i} Y_{\mathrm{f}}=\mathrm{PPF}\right)$

\begin{tabular}{|c|c|c|c|c|c|c|c|c|}
\hline $\begin{array}{l}\text { Date } \\
\text { (June) }\end{array}$ & Stn & $\begin{array}{l}\text { Time of cast } \\
\text { (GMT) }\end{array}$ & $\begin{array}{l}\text { Lat. } \\
\text { (N) }\end{array}$ & $\begin{array}{l}\text { Long. } \\
\text { (W) }\end{array}$ & $\begin{array}{c}\text { Chla } \\
\left(\mu g l^{-1}\right)\end{array}$ & $\begin{array}{c}K_{d} \\
\left(\mathrm{~m}^{-1}\right)\end{array}$ & $\begin{array}{c}\text { PAR }(\mu \mathrm{mol} \\
\left.\text { quanta } \mathrm{m}^{-2} \mathrm{~s}^{-1}\right)\end{array}$ & Photoinhib. \\
\hline 19 & $\mathrm{~A}$ & $16: 51$ & $60^{\circ} 00^{\prime}$ & $19^{\circ} 50^{\prime}$ & 1.02 & 0.120 & 1511 & \\
\hline 20 & $B$ & $15: 33$ & $61^{\circ} 40^{\prime}$ & $19^{\circ} 57^{\prime}$ & 1.02 & 0.227 & 1673 & $Y_{i}$ \\
\hline 21 & $c$ & $15: 04$ & $63^{\circ} 11^{\prime}$ & $21^{\circ} 33^{\prime}$ & 1.70 & 0.200 & 1511 & \\
\hline 21 & $\mathrm{D}$ & $19: 07$ & $63^{\circ} 35^{\prime}$ & $21^{\circ} 21^{\prime}$ & 0.82 & 0.136 & 1238 & $Y$ \\
\hline 22 & $E$ & $09: 41$ & $61^{\circ} 31^{\prime}$ & $22^{\circ} 35^{\prime}$ & 0.81 & 0.204 & 278 & $Y$ \\
\hline 22 & $\mathrm{~F}$ & $18: 24$ & $60^{\circ} 51^{\prime}$ & $22^{\circ} 39^{\prime}$ & 2.27 & 0.190 & 375 & $Y$ \\
\hline 23 & $\mathrm{G}$ & $10: 41$ & $61^{\circ} 06^{\prime}$ & $22^{\circ} 42^{\prime}$ & 0.96 & 0.210 & 1673 & \\
\hline 23 & $\mathrm{H}$ & $18: 56$ & $61^{\circ} 06^{\prime}$ & $22^{\circ} 43^{\prime}$ & 0.77 & 0.204 & 375 & $Y$ \\
\hline 24 & I & $14: 57$ & $60^{\circ} 54^{\prime}$ & $22^{\circ} 54^{\prime}$ & 2.62 & 0.217 & 1849 & $Y_{\mathrm{f}}$ \\
\hline 25 & J & $12: 34$ & $60^{\circ} 54^{\prime}$ & $22^{\circ} 39^{\prime}$ & 2.4 .1 & 0.197 & 750 & $Y$ \\
\hline 26 & K & $09: 36$ & $59^{\circ} 38^{\prime}$ & $20^{\circ} 57^{\prime}$ & 1.30 & 0.142 & 370 & \\
\hline 27 & L & $16: 47$ & $61^{\circ} 12^{\prime}$ & $15^{\circ} 08^{\prime}$ & 2.40 & 0.192 & 413 & $Y$ \\
\hline 28 & $M$ & $14: 50$ & $61^{\circ} 10^{\prime}$ & $15^{\circ} 10^{\prime}$ & 2.56 & 0.200 & 413 & \\
\hline 28 & $N$ & $19: 16$ & $61^{\circ} 07^{\prime}$ & $15^{\circ} 08^{\prime}$ & 2.79 & 0.223 & 176 & \\
\hline 29 & $\mathrm{O}$ & $10: 03$ & $61^{\circ} 05^{\prime}$ & $14^{\circ} 55^{\prime}$ & 2.40 & 0.207 & 502 & \\
\hline 30 & $\mathrm{P}$ & $16: 07$ & $61^{\circ} 00^{\prime}$ & $14^{\circ} 42^{\prime}$ & 1.38 & 0.160 & 1673 & \\
\hline
\end{tabular}
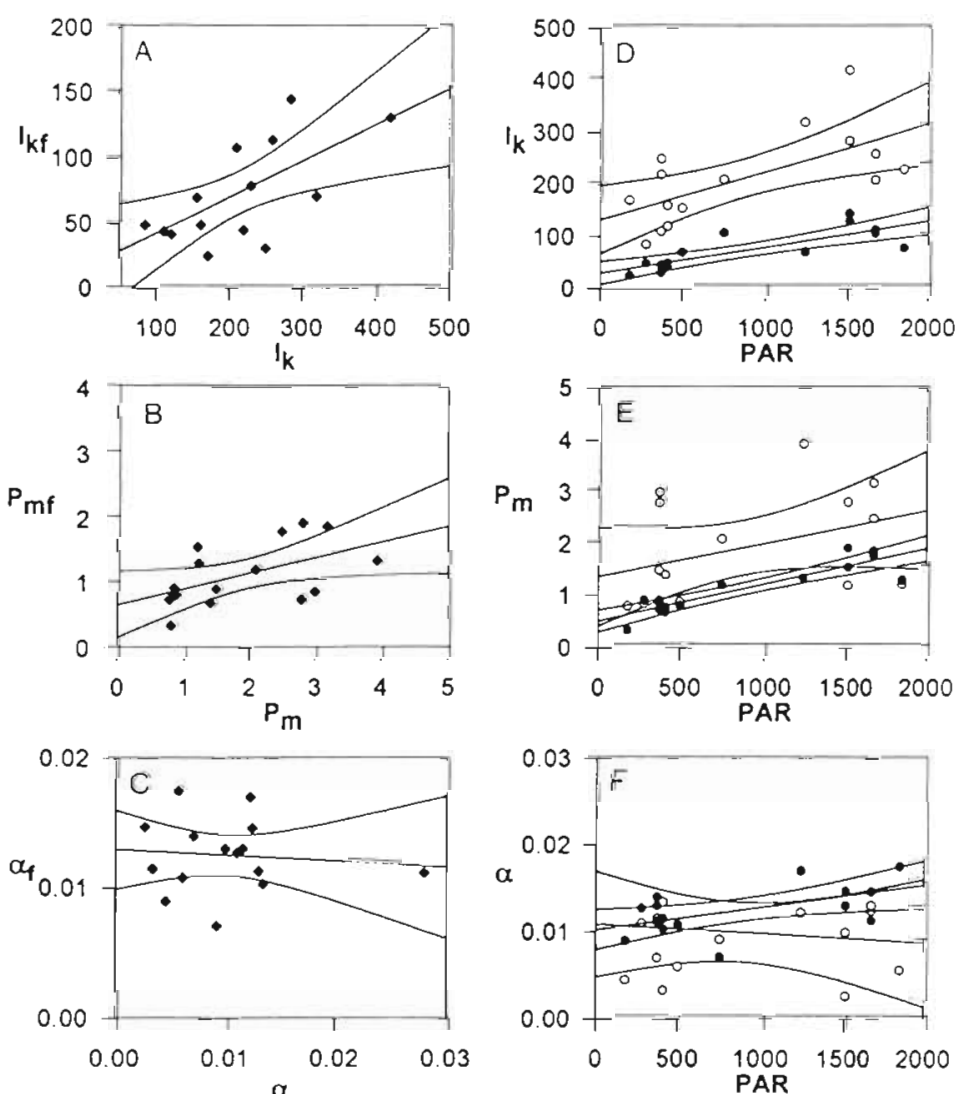

Fig. 4. Regression plots of (A) $I_{k 1} v s I_{k}(\mathrm{n}=14),(\mathrm{B}) P_{\mathrm{m} 1}$ vs $P_{\mathrm{m}}(\mathrm{n}=15)$, and (C) $\alpha_{f}$ vs $\alpha$ (n=15); and of (D) $I_{k}$ vs PAR ( $\mu$ mol quanta $\mathrm{m}^{-2} \mathrm{~s}^{-1}$ ), (E) $P_{\mathrm{m}}$ vs PAR, and $(F) \propto$ vs PAR ( $\mu$ mol quanta $\mathrm{m}^{-2} \mathrm{~s}^{-1}$ ) from both approaches, PPF $(\bullet)$ and ${ }^{14} \mathrm{C}(0)$. Additional solid lines denote $95 \%$ confidence limits. The units for $P_{\mathrm{m}}\left(P_{\mathrm{ri}}\right)$, and $\alpha\left(\alpha_{1}\right)$ are $\mathrm{mgC}(\mathrm{mg} \mathrm{chl} \mathrm{a})^{-1} \mathrm{~h}^{-1}$ and $\mathrm{mg} \mathrm{C}$ $(\mathrm{mg} \mathrm{chl} a)^{-1} \mathrm{~h}^{-1}$ ( $\mathrm{\mu mol}$ quanta $\left.\mathrm{m}^{-2} \mathrm{~s}^{-1}\right)^{-1}$, respectively a discrepancy between the 2 measurements of $I_{k}$ suggesting a systematic error in one or both.

A significant relationship was also observed between $P_{\mathrm{m} i}$ and $P_{\mathrm{m}}$ (Table 3), although the percentage of the variance explained by the relationship was not as high as for $I_{k}$. As observed for $I_{k}$ and $I_{k \mathrm{f}}$, most values of $P_{\mathrm{m}}$ were higher than the corresponding values for $P_{\mathrm{mf}}$ (Fig. 4B). The product of $\alpha_{\mathrm{f}}$ and $I_{\mathrm{kf}}$ provides an alternative estimate of $P_{\mathrm{mf}}$ (denoted here as $\left.P_{\mathrm{mf}}{ }^{\circ}\right)$ for comparison with the ${ }^{14} \mathrm{C}$ measurements of productivity. These $P_{\mathrm{m}} i^{\circ}$ data showed a significant relationship with $P_{\mathrm{m}}$ with a similar proportion of the variance being explained by the relationship as for $P_{\mathrm{mi}}$ and $P_{\mathrm{m}}$ (Table 3 )

There was no correlation between measurements of $\alpha$ and $\alpha_{f}$ (Fig. 4C). However, a comparison of $\Delta \phi_{\mathrm{m}}$ data ( 2 to $7 \mathrm{~m}$ ) from PPF and $\alpha$ (discrete depths $2,5,7 \mathrm{~m}$ ) revealed a significant relationship with $55 \%$ of the variance explained by the linear regression (Table 3 ). These 2 parameters are not identical measures of photosynthetic rates but are expected to be linearly related (Kolber \& Falkowski 1993) with an offset in $\Delta \phi_{\mathrm{m}}$ expected; the slope of the regression relationship was ca 7 (Table 3 ).

\section{Relationship with PAR}

The relationships between both $I_{k}$ and $I_{k f}$ and PAR were significant (Fig. 4D, Table 4), as were those between $P_{\mathrm{m} t} P_{\mathrm{mi}}$ and $\alpha_{\mathrm{f}}$ and PAR 
(Figs. 4E, F, Table 4). In contrast, neither $P_{\mathrm{m}}$ nor $\alpha$ showed a significant relationship with PAR (Figs. 4E, F, Table 4). As was the case for $\alpha, \Delta \phi_{\mathrm{m}}$ was not correlated with PAR (Table 4).

\section{Relationship with time of day and date (bloom status)}

The variations of all 3 parameters, $I_{k}, P_{\mathrm{m}}$ and $\alpha$, derived from both techniques, with date (used as a proxy for bloom status) and time of day for all 16 deployments are shown in Fig. 5. While there was considerable variability in the data obtained during this study, there are general patterns common to $I_{k}$ derived from both approaches and to a lesser extent to $P_{\mathrm{m}}$. $I_{k}$ derived from both approaches showed a downward trend with date suggesting that the photosynthetic activity of the phytoplankton assemblage was decreasing over the duration of the cruise (Fig 5A). A similar trend was evident for $P_{\mathrm{m}}$ plotted against date (Fig. 5B). PPF data from Fig. 5B and to a lesser extent Fig. 5A suggest that the data points obtained on June 30 are outliers. There were no observable trends for $\alpha$ derived from the 2 techniques with bloom status (Fig. 5C). The values of both $I_{k f}$ and $P_{\mathrm{mt}}$ were generally lower, and displayed less variability, than those measured by the ${ }^{14} \mathrm{C}$ method, indicating a systematic difference or possibly an error in one or both measurements. Generally the values of $\alpha_{i}$ were slightly higher than, and displayed less variability with date than was observed for $\alpha$ and date (Fig. 5C).

Plots of the magnitude of the photosynthetic parameters against time of day (Fig. 5D-F) generally displayed more variability than observed for bloom status (Fig. 5A-C). There was no evidence of diel periodicity in $P_{\mathrm{m}}$ or $\alpha$ values (Fig. 5E, F), but $I_{k}$ values derived from both approaches were relatively low in the morning and exhibited a mid-afternoon peak (albeit with some noise). In the period towards evening, however, $I_{k 1}$

Table 3. Regression analysis of a comparison of photosynthetic parameters derived from the 2 techniques. In all cases $\mathrm{n}=15$ (Stn $\mathrm{P}$ excluded). "denotes regression significant at $\mathrm{p}<0.05 ; P_{\mathrm{ml}}{ }^{*}$ denotes the product of $\alpha_{1}$ and $I_{k 1}$

\begin{tabular}{|lll|}
\hline Parameter & Relationship & $\mathrm{r}^{2}$ \\
\hline$l_{k t}$ & $15.22+0.275 I_{k}$ & $39.6 \%^{\mathrm{a}}$ \\
$P_{\mathrm{nit}}$ & $0.664+0.242 P_{\mathrm{m}}$ & $27.2 \%^{\circ}$ \\
$\alpha_{\mathrm{i}}$ & Not significant & \\
$P_{\mathrm{mi}}$ & $0.034+0.132 P_{\mathrm{m}}$ & $24.8 \%^{\circ}$ \\
$\Delta \Phi_{\mathrm{m}}$ & $0.27+6.70 \alpha$ & $55.0 \%^{\circ}$ \\
\hline
\end{tabular}
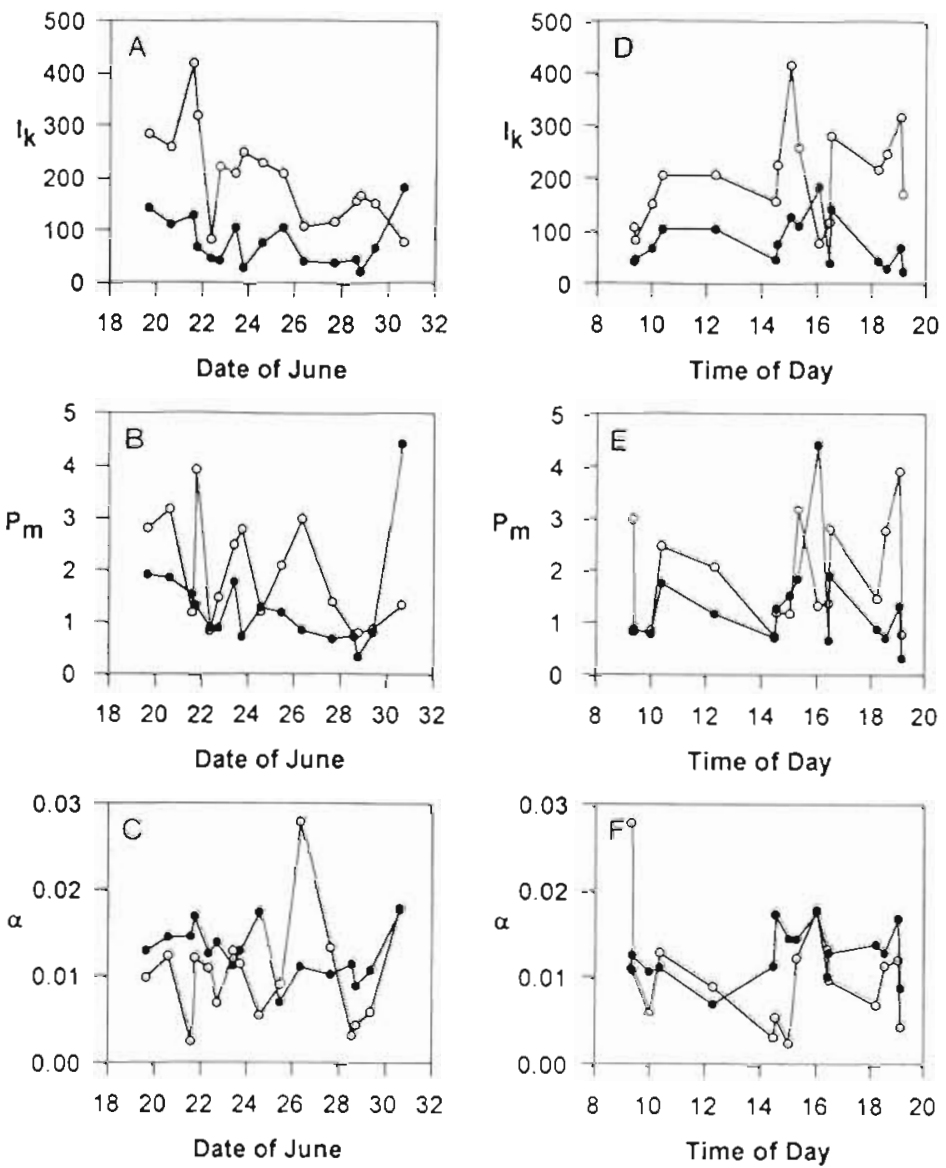

Fig. 5. Parameters derived from $\operatorname{PPF}(\bullet)$ and ${ }^{14} \mathrm{C}(0)$ plotted against date of June, (A) $I_{k},(B) P_{m},(C) \alpha$; and against time of day (end of upcast) for (D) $I_{k}$, (E) $P_{\mathrm{m}}$, and (F) $\alpha$

decreased whereas values of $I_{k}$ remained high (Fig. 5D), suggesting a possible artifact in one or both of these measurements.

The suggestion of diel periodicity for $I_{k}$ was investigated further by comparing values obtained on June $21,22,23$ and 28 , when sampling was conducted at the

Table 4. Regression analysis of photosynthetic parameters, derived from the 2 techniques, and PAR (at the time of the CTD upcast). In all cases $n=15$ (Stn $\mathrm{P}$ excluded). "denotes regression significant at $p<0.05$

\begin{tabular}{|lll|}
\hline Parameter & Relationship & $\mathrm{r}^{2}$ \\
\hline$I_{\mathrm{kf}}$ & $30.2+0.0502$ PAR & $65.6 \% \%^{\circ}$ \\
$I_{\mathrm{k}}$ & $132.9+0.0924 \mathrm{PAR}$ & $42.6 \%^{\circ}$ \\
$P_{\mathrm{ml}}$ & $0.51+0.00702$ PAR & $80.6 \%^{\circ}$ \\
$P_{\mathrm{m}}$ & $1.36+0.000643 \mathrm{PAR}$ & $14.7 \%$ \\
$\alpha_{\mathrm{i}}$ & $0.010+0.000003$ PAR & $38.0 \% \%^{\circ}$ \\
$\alpha$ & Not significant & \\
$\Delta \phi_{\mathrm{m}}$ & Not significant & $66.6 \%$ \\
$P_{\mathrm{ml}}{ }^{\circ}$ & $0.135+0.001$ PAR & \\
\hline
\end{tabular}


same station at different times of day (Table 2). On June 21 , values of $I_{k}$ were higher in mid-afternoon than in early evening for both techniques (Fig 5A). This trend was also observed on June 28 for $I_{k f}$ but not for $I_{k}$. On June 22, similar values of $I_{k}$ were noted from samples drawn before 10:00 h and after 18:00 h (Fig. 5A), whereas on June 23 samples drawn after 10:00 h exhibited a higher $I_{k f}$ than at ca 19:00 h (Fig. 5A). Although there was no evidence of diel periodicity for $P_{\mathrm{m}}$ or $P_{\mathrm{m} f}$ (Fig. 5E), on June $21-23$ and $28, P_{\mathrm{mf}}$ values from late morning/mid afternoon were higher than those in the evening (Fig. 5B). In general, the opposite trend was noted for $P_{\mathrm{m}}$

Plots of $I_{k}$ and $P_{\mathrm{m}}$ vs PAR indicated that they were functionally related to incident light (Fig, 4D, E). Thus some of the variability observed in Fig. 5D, E may be light-related; regression analysis showed that a greater percentage of the variance is explained for the PPF measurements vs PAR than for ${ }^{14} \mathrm{C}$ vs PAR (Table 4). The relationship between $\alpha$ and both time of day and PAR was not significant (Fig. 5F, Table 4). It was evident from these analyses that PAR is a forcing function of $I_{k}$ and $P_{\mathrm{m}}$

\section{DISCUSSION}

A comparison of $I_{k}, \alpha_{1}$ (or $\Delta \phi_{\mathrm{m}}$ ) and $P_{\mathrm{m}}$ obtained from the 2 techniques indicated that the correlative relationships between the estimates varied considerably, being strongest between $I_{k}$ and $I_{k f}, \Delta \phi_{\mathrm{m}}$ and $\alpha$ and weakest for $\alpha_{i}$ and $\alpha$. (Table 3). These changes in the percentage of the variance explained by the 2 approaches may be due to methodological considerations (including any assumptions in calculation steps) or artifacts between 2 radically different techniques for measuring production, based on different time scales. $I_{k}$ appears to be a more independent measurement of the irradiance at which photosynthesis is saturated (i.e. the change from linearly proportional to $I$ to independent of $I$, and the value of $I_{k f}$ obtained depends only on the accuracy of measurement by the PPF of one parameter (Kolber \& Falkowski 1993). Assessment of $\alpha$ depends on chlorophyll a estimates, and comparison of values of this parameter derived from ${ }^{14} \mathrm{C}$ and $\mathrm{PPF}$ techniques absolutely requires that the measurements are done on the same water sample. The $P_{\mathrm{n}}$ parameter is again dependent on the value of the chlorophyll a biomass and the value is very sensitive to the measurement of this independent parameter (Kolber \& Falkowski 1993). As observed (Fig. 4B), the variability in $P_{\mathrm{m}}$ will be greater than in $P_{\mathrm{m} t}$, partly because of variability in the measured value of chlorophyll, whereas $P_{\mathrm{rnt}}$ is independent of this measurement, normalized as per Eq. (12) (Kolber \& Falkowski 1993). However, it must be noted that in all comparisons photosynthetic performance at different depths is being contrasted (see 'Results').

\section{$I_{k}$}

There were obvious patterns common to $I_{k}$ and $I_{k i}$ which provided convincing evidence that the 2 techniques were essentially measuring the same basic property or characteristics of the phytoplankton assemblage in this region. Laboratory culture studies have yielded good agreement between $I_{k}$ values derived from oxygen evolution measurements and those obtained from fluorescence data (Kroon et al. 1993). In the present study, values of $I_{k f}$ were generally considerably lower than those measured by the ${ }^{14} \mathrm{C}$ method (Fig. 4A), indicating a systematic difference or possibly an error in one measurement. Estimates of the magnitude of error which could be attributed to known differences between the techniques is presented in Table 5. The underwater PAR measurements (on the CTD frame) which were used to calculate the values of $I_{k f}$ and $P_{\mathrm{mf}}$ were known to be about $20 \%$ less than the surface shipboard measurements, accounting for some of the difference. It is also possible that the selection of $I_{k}( \pm 1.0 \mathrm{~m})$ from the PPF profiles based on the location of a point of inflection (see Fig. 2) may introduce some error into the calculation of $I_{k f}$, particularly if the depth of $I_{k}$ is shallow, and thus contribute to the observed offset (Fig. 4A). Other systematic differences such as the use of conversion factors (photosynthetic quotientssee 'Methods') and different incubation periods were likely to have little effect on the magnitude of the observed values for these techniques.

The main discrepancy between the observed values probably arose from the different spectral quality for the 2 measurements, the $W$-halogen lamps used for the ${ }^{14} \mathrm{C}$ incubations having a higher red to blue photon

Table 5. Factors which could account for the observed discrepancies between $I_{k}$ and $I_{k}$, and between $P_{\mathrm{n}}$ and $P_{\mathrm{mr}}$. Estimated discrepancy is \% over- or under-estimation of values derived from PPF technique relative to those derived from ${ }^{14} \mathrm{C}$ technique. $\mathrm{PQ}$ denotes photosynthetic quotient. Differences in sampling depths will mainly influence the estimation of $\alpha$ and $\alpha_{i}$

\begin{tabular}{ll} 
Factor & $\begin{array}{l}\text { Estimated } \\
\text { discrepancy }\end{array}$ \\
\hline $\begin{array}{ll}\text { Data conversion using PQ } \\
\text { Location of PAR sensors }\end{array}$ & Minimal \\
Spectral differences between light sources & ca $20 \%$ less \\
Selection of $I_{k 1}$ from profiles & $\pm 10 \%$ \\
Differing 'incubation' periods & ca $20 \%$ less
\end{tabular}


ratio than incident light and differing from the spectrum of the natural underwater light in which the PPF measurements were made. As a consequence of the coccolithophore bloom, the in-water transmission spectrum in this study was characterised by a high blue content and was nearly uniform from 400 to $550 \mathrm{~nm}$. In contrast, the spectrum of the $W$-halogen lamp is centred at close to 700 $\mathrm{nm}$. The major photosynthetic pigments measured during the cruise (chlorophylls and carotenoids) absorb light at up to $500 \mathrm{~nm}$ (Bidigare et al. 1990, C. Trees, this cruise, pers. comm) and from 650 to 700 $\mathrm{nm}$ (chlorophylls only). In order to quantify these spectral differences, a normalisation procedure was carried out, in which the in-water transmission spectra (obtained at 410,450,490,520,560 and 630 nm using optical sensors fitted to the CTD and as described by Aiken \& Bellan 1990) was interpolated and compared with that of the lamp. The ratio of the quanta absorbed in seawater to those absorbed by the lamp is ca 2. On this basis, the magnitude of $P_{\mathrm{mt}}$ and $I_{k f}$ will be ca 0.5 of $P_{m}$ and $I_{k}$ (Table 5). Differences of this magnitude are observed (Fig. 4).

$$
P_{\mathrm{m}}
$$

The values of $P_{\mathrm{m}}$ derived from the 2 approaches exhibited a significant relationship (Table 3 ), which indicated that the 2 techniques were essentially measuring the same basic property of the resident microalgal population. In assessing variability of the $P_{\mathrm{n}}$ data sets, it should be noted that the calculation of $P_{\mathrm{mi}}$ is obtained from 2 parameters which are measured, and 2 which are assumed $\left(\sigma_{\mathrm{ps} 2}\right.$ and $\left.n_{\mathrm{ps} 2}\right)$ and thus assigned the same value for all stations, which reduces the variability of $P_{\mathrm{mif}}$ (Kolber \& Falkowski 1993). In addition, Emiliania huxleyi has not so far been used in a lab-based evaluation of the PPF technique. However, despite the assumptions used in (Eq. 8) of Kolber \& Falkowski (1993) concerning bio-

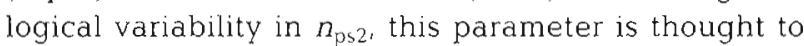
vary considerably less than others such as $\Delta \phi_{\mathrm{m}}$ (Kolber \& Falkowski 1993). After consideration of the likely effect of the spectral differences between the light sources used (Table 5), there was reasonable correspondence between the range of values noted for $P_{\mathrm{m}}$ and $P_{\mathrm{mi}}$.

\section{$\alpha$}

In contrast to both $P_{\mathrm{m}}$ and $I_{k}$, there was no significant relationship between values of $\alpha$ and $\alpha_{f}$ (Fig. 4C). The photosynthetic rate constant at low light $\alpha$ is derived
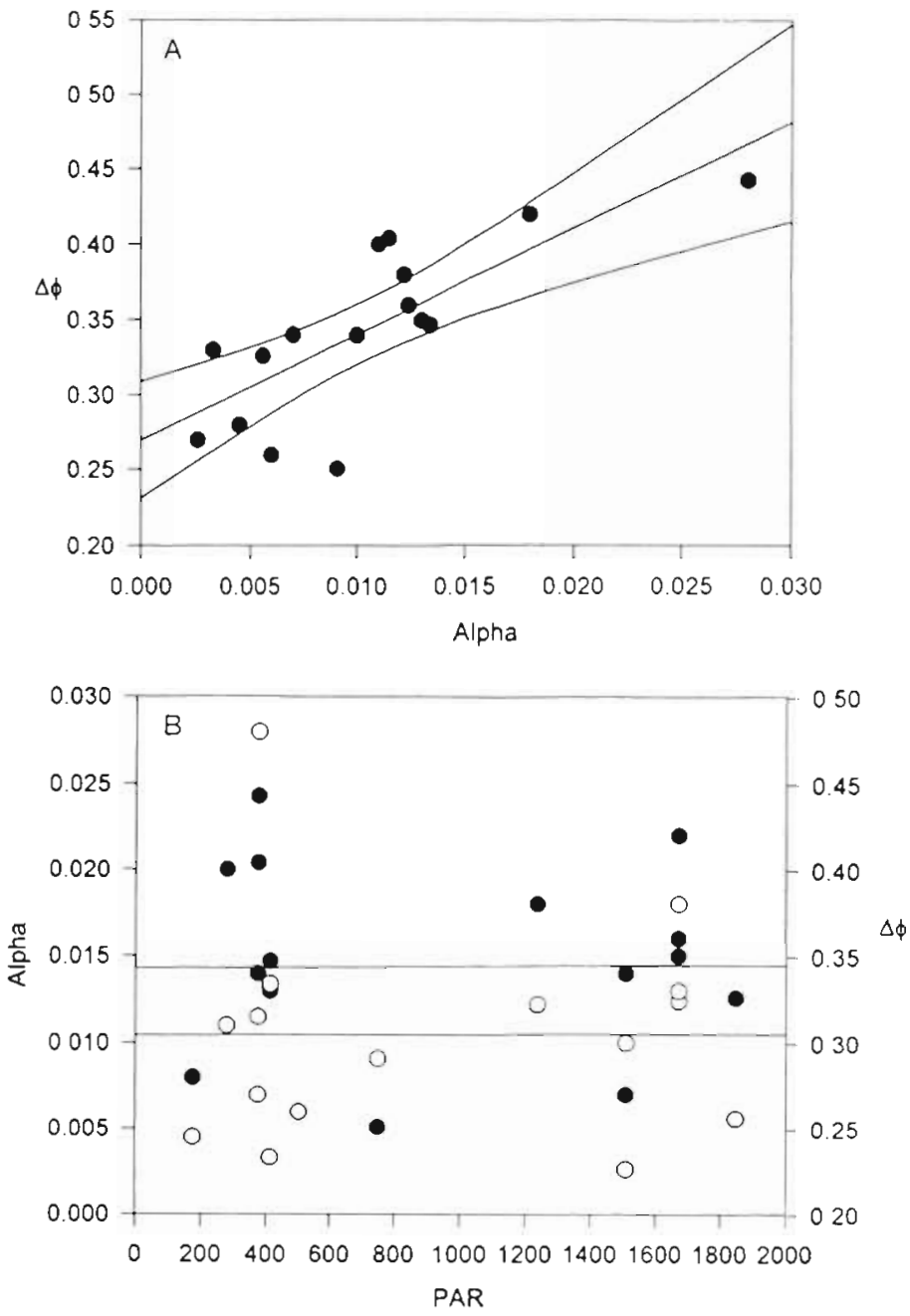

Fig. 6. Regression plots of (A) $\Delta \phi_{\mathrm{m}}$ vs $\alpha,(\mathrm{B}) \Delta \phi_{\mathrm{m}}(\bullet)$ and $\alpha(O)$ vs PAR ( $\mu$ mol quanta $\mathrm{m}^{-2} \mathrm{~s}^{-1}$ ). Additional solid lines denote $95 \%$ confidence limits. ( $\Delta \phi_{m 1}$ is dimensionless)

from the slope of the linear part of these curves. The sampling of phytoplankton from different depths may be responsible in part for the lack of a relationship between $\alpha$ and $\alpha_{f}$; the $\alpha$ values were derived from water samples from 2,5 , or $7 \mathrm{~m}$ whereas $\alpha_{i}$ were for depths generally greater than $15 \mathrm{~m}$. Thus $\alpha_{\mathrm{f}}$ was determined from water column measurements, with potentially different phytoplankton 'samples' at each depth, even though the phytoplankton assemblage is probably 'constant' through the surface mixed layer. In the present study, the particle mixed layer depth (derived from beam attenuation measurements) was ca $20 \mathrm{~m}$ (Holligan et al. 1993) indicating that most of the data used to estimated $\alpha_{1}$ were obtained in the mixed layer between 15 and $20 \mathrm{~m}$ depth (Fig. 2). Therefore, $\Delta \phi_{\mathrm{m}}$ is a more appropriate measurement of local photosynthetic rates at the shallow depths and the comparison with $\alpha$ was better as shown in Fig. 6A. Note that in 
Fig. $6 \mathrm{~B}$, both $\alpha$ and $\Delta \phi_{\mathrm{m}}$ from the PPF are poorly correlated with incident PAR, which suggest that some other factor, such as nutrient availability, may exert more control over both $\alpha$ and $\Delta \phi_{m}$ than PAR itself.

\section{Comparison with other $P$ vs $I$ data from the North Atlantic}

Sathyendranath et al. (1995) recently presented a map of the station positions of $P$ vs $I$ experiments conducted in the North Atlantic. Although they use a dataset of $>1800 P$ vs $I$ experiments in their analysis, all of these were obtained in the western Atlantic (west of the $40^{\circ} \mathrm{W}$ meridian) The NE Atlantic was the focus of the recent Joint Global Ocean Flux Study North Atlantic Bloom Experiment (Ducklow \& Harris 1993); however few attempts were made to directly assess the photosynthetic characteristics of the phytoplankton. during these studies (Boyd et al. unpubl.). The magnitude and range of the $P$ vs $I$ characteristics obtained in the present study compare favorably with those from the post-diatom bloom and diatom bloom studies in the vicinity of $47^{\circ} \mathrm{N}, 20^{\circ} \mathrm{W}$ during late spring 1989 and 1990, respectively (Boyd et al. unpubl.), but are less than those estimated by Kiddon et al. (1995) based on dissolved oxygen productivity measurements and a modelling approach. Kiddon et al. (1995) suggest that these physical and procedural differences between their study and 'conventional' $P$ vs $I$ data will likely limit the ability to compare datasets. Both the small $P$ vs $I$ database for this region and the differing estimates of the magnitude of $P$ vs $I$ characteristics emphasize the need for improved temporal and spatial resolution for $P$ vs $I$ datasets from this region

Olaizola et al. (1996) presented data on variations in the fluorescence-based maximum quantum efficiency of photosynthesis along a transect from the Canary Islands to the West Atlantic, north of $40^{\circ} \mathrm{N}$. Although the aims of their study were different to, and their stations were considerably further south than, those in the present study, the magnitude of values of $\Delta \phi_{m}$ derived from the PPF in this study (see Fig. 2) were comparable to those reported by Olaizola et al. (1996). The observed values suggest that the coccolithophores in the present study were physiologically stressed corresponding to the decline of the bloom (Holligan et al 1993).

\section{Diel periodicity/evidence of photoacclimation?}

In the present study, a comparison of diel variations in $I_{k}$ and $P_{\mathrm{m}}$, on 4 days when more than one measurement was made at one station, supported the initial suggestion of diel periodicity for $I_{k l}$ and in addition revealed that while values of $P_{\mathrm{mf}}$ declined later in the day, the magnitude of $P_{\mathrm{m}}$ increased with time. Diel variations in $I_{k}$ and $P_{\mathrm{m}}$ have been observed for marine phytoplankton (MacCaull \& Platt 1975, Prezelin \& Sweeney 1977, Putt \& Prezelin 1985), and are associated with the endogenous periodicity of the phytoplankton (Prezelin \& Sweeney 1977).

Prezelin \& Matlick (1980) noted that $I_{k}$ exhibited a diel periodicity increasing in the morning and decreasing in the early evening. In the present study, $I_{k 1}$ decreased in the period towards evening suggesting a relaxation from non-photochemical quenching (Greene et al. 1994), while the values of $I_{k}$ remained relatively high (for example see June 23 in Fig. 5A). It is possible that for $I_{k i}$, the irradiance measured, late in the day, was not representative of the adaptive state of the phytoplankton at 5 to $10 \mathrm{~m}$ depth. However, it is more likely that the $I_{k}$ determined for the ${ }^{14} \mathrm{C}$ technique was overestimated, and that the $2 \mathrm{~h}$ incubation may have slowed down this relaxation due to photoacclimation to higher irradiances in the artificial light gradient incubator, comparable to those observed earlier in the day. The higher values of $P_{\mathrm{m}}$ noted in the early evening may also have been due to such experimental artifacts. Time scales of photoadaptation of this order have previously been observed for microalgae (Henley 1993). Photoinhibition was seldom observed in the PPF profiles but was noted 6 times in the ${ }^{14} \mathrm{C}$ dataset, usually when relatively low ambient irradiances had been recorded (see Table 2) and may thus provide evidence of photoadaptation to high light conditions within the incubator superimposed on the photosynthetic periodicity on these time scales.

The general decline in $I_{k}$ and $P_{\mathrm{m}}$ derived from both techniques over the course of the study (Fig. 5A, B) concurs with Fernandez et al. (1993) and Holligan et al. (1993), who observed a decline in the activity of the coccolithophorid bloom over a wide area, based on rates of calcification, photosynthesis and inferred from satellite imagery over this time.

\section{Regressions of photosynthetic parameters with PAR}

Regressions of photosynthetic parameters with PAR (at the time of the upcast) generally showed stronger relationships with PPF than ${ }^{14} \mathrm{C}$. However the selection of a PAR value at the time of the upcast may be inappropriate since photosynthetic parameters such as $P_{\mathrm{m}}$ are variable and dependent on the previous irradiance exposure (Neale \& Marra 1985). They suggested that irradiance history includes 2 primary time scales of light history effects, including a short $(<2$ h) scale which reflects direct effects of high light on light har- 
vesting and electron transport. The time scale of the light history used in the present study may be more appropriate to the instantaneous PPF measurements than to the time integrated ${ }^{14} \mathrm{C}$ data.

\section{CONCLUSIONS}

Despite several uncertainties, such as spectral differences between light sources, photoacclimation, or the assumption of $P Q$ values, involved in comparing these 2 radically different techniques, there is reasonable correlation between the datasets for $P_{m}, I_{k}$, and for $\Delta \phi_{\mathrm{m}}$ and $\alpha$. Correction for spectral differences, via spectral normalisation, explained the majority of the ca 3 -fold differences between the absolute values derived for the 2 techniques. These findings demonstrate that key photosynthetic rate parameters can be derived in situ, rapidly, and without the experimental artifacts caused by prolonged incubations. A rapid vertical profiling system of this nature or one towed in undulating mode behind a research vessel (e.g. Aiken \& Bellan 1990) will permit surveys of photoadaptive parameters on time scales matching the recent advances in the temporal extents of multidisciplinary in situ measurement systems and provide ground truth data for the formulation, development and validation of basin scale models needed to more accurately estimate primary production over wide spatial scales (Balch et al. 1992).

Acknowledgements. We acknowledge the help and assistance provided by the officers and crew of RRS 'Charles Darwin' Thanks to Ian Bellan for assistance with PPF vertical profiling (Plymouth Marine Laboratory, Plymouth, UK), to Paul Falkowski for the loan of the instrument (Brookhaven National Laboratory, USA) and to Charles Trees for the personal communication (CHORS, San Diego State University, USA). We are grateful for the insıghts and umprovements to the manuscript provided by Dr M Dring and 2 anonymous reviewers. This work was part of the UK's Natural Environment Research Council's BOFS CRP. P.B. was supported by grant GST/02/381 to 1. Joint/G. Savidge. Thus is BOFS contribution no. 228. This research (Z.K.) was supported by US Department of Energy under contract DE-AC02-76CH000016 and by NASA under grant UPN 161-35-05-08.

\section{LITERATURE CITED}

Aiken J, Bellan I (1986) A simple hemisphencal logarithmic light sensor In: Blizard MA (ed) Ocean Optıcs VIII, Proc SPIE 637:211-216

Aiken J, Bellan I (1990) Optical oceanography: an assessment of a towed method. In: Herring PJ, Campbell AK, Whitfield M, Maddock L (eds) Light and life in the sea. Cambridge University Press, Cambridge, p 39-57

Balch W, Evans R, Brown J, Feldman G, McClain C, Esais W (1992) The remote sensing of ocean productivity: use of a new data compilation to test satellite algorithms. J Geophys Res 97:C2, 22279-22293
Bidigare RR, Ondrusek ME, Morrow JH, Kiefer DA (1990) In vivo absorption properties of algal pigments. SPIE Ocean Optics 1302:290-302

Cullen JJ, Lewis MR (1988) The kinetics of algal photoadaptation in the context of vertical mixing. J Plankton Res 10: $1039-1063$

Ducklow HW, Harris RP (1993) Introduction to the JGOFS North Atlantic Bloom Experment. Deep Sea Res II 40:1-8

Eppley RW (1980) Estimating phytoplankton growth rates in the central oligotrophic oceans. In: Falkowski PG (ed) Primary productivity in the sea. Brookhaven Symp Biol 31. Plenum, New York, p 231-242

Falkowskı PG, Kolber Z (1995) Variations in chlorophyll fluorescence yields in phytoplankton in the worlds oceans. Aust J Plant Physiol 22:341-355

Falkowski PG, Kolber Z, Fujita Y (1988) Effects of redox state on the dynamics of Photosystem II during steady-state photosynthesis in eucaryotic algae. Biochim Biophys Acta 933:432-443

Falkowski PG, Wyman K, Ley AC, Mauzerall DC (1986) Relationship of steady-state photosynthesis to fluorescence in eucaryotic algae. Biochim Biophys Acta 849: 183-192

Falkowski PG, Ziemann D, Kolber Z, Bienfang PK (1991) Nutrient pumping and phytoplankton response in a subtropical mesoscale eddy. Nature 352:55-58

Fernandez E, Boyd PW, Holligan PM, Harbour DS (1993) Production of organic and inorganic carbon within a large scale coccolithophore bloom in the northeast Atlantic Ocean. Mar Ecol Prog Ser 97:271-285

Fitzwater SE, Knauer GA, Martın JH (1982) Metal contamination and its effect on prumary production methods. Limnol Oceanogr 27:544-551

Geider RJ, Greene RM, Kolber Z, MacIntyre HC, Falkowski PG (1993) Fluorescence assessment of the maximum quantum efficiency of photosynthesis in the western North Atlantic. Deep Sea Res 40:1205-1224

Geider RJ, Osborne BA (1992) Algal photosynthesis-the measurement of algal gas exchange. Chapman and Hall, New York

Govingee (1975) (ed) Bioenergetics of photosynthesis. Academic Press, New York

Greene RM, Kolber Z, Swift DG. Tindale NW, Falkowski PG (1994) Physiological limitation of phytoplankton photosynthesis in the eastern equatorial Pacific determined from variability in the quantum yield of fluorescence. Limnol Oceanogr 39: 1061-1074

Henley W J (1993) Measurement and interpretation of photosynthetic light-response curves in algae in the context of photonhibition and diel changes. J Phycol 29: 729 - 739

Holligan PM, and others (1993) A biogeochemical study of the coccolithophore Emiliania huxleyi in the North Atlantic. Global Biogeochem Cycles 7:879-900

Joint IR, Pomroy AJ (1986) Photosynthetic characteristics of nanoplankton and picoplankton from the surface mixed layer. Mar Biol 92:465-474

Joint LR, Pomroy AJ, Savidge G, Boyd PW (1993) Size-fractionated primary productivity in the northeast Atlantic in May-July 1989. Deep Sea Res II 40:423-440

Kiddon J, Bender ML, Marra J (1995) Production and respiration in the 1989 North Atlantic spring bloom, an analysis of irradiance-dependent changes. Deep Sea Res I 42: $553-576$

Kiefer DA, Reynolds RA (1992) Advances in understanding phytoplankton fluorescence and photosynthesis. In: Falkowski PG, Woodhead AD (eds) Primary productivity and biogeochemical cycles in the sea. Plenum Press, New York, p 155-174 
Kolber Z, Falkowski PG (1992) Fast Repetition Rate (FRR) fluorometer for making in situ measurements of primary productivity. Proc Ocean 92 Conference, Newport, Rhode Island, $\mathrm{p} 737-741$

Kolber Zr Falkowski PG (1993) Use of active fluorescence to estimate phytoplankton photosynthesis in situ. Limnol Oceanogr 38: 1646-1665

Kolber Z, Wyman KD, Falkowski PG (1990) Natural variability in photosynthetic energy conversion efficiency: a field study in the Gulf of Maine. Limnol Oceanogr 35:72-79

Kolber Z, Zehr J, Falkowski PG (1988) Effects of growth irradiance and nitrogen limitation on photosynthetic energy conversion in photosystem II. Plant Physiol 88:923-929

Kroon B, Prezelin BB, Schofield O (1993) Chromatic regulation of quantum yields for photosystem II charge separation, oxygen evolution, and carbon fixation in Heterocapsa pygmaea (Pyrrophyta). J Phycol 29:453-462

Laws EA (1990) Photosynthetic quotients, new production and net community production in the open ocean. Deep Sea Res 38:143-167

Lederman TC, Tett $\mathrm{P}$ (1981) Problems in modelling the photosynthesis-light relationship for phytoplankton. Bot Mar 24: $124-134$

Lewis MR, Horne EPW, Cullen JJ, Oakey NS, Platt T (1984) Turbulent motions may control phytoplankton photosynthesis in the upper ocean. Nature 311:49-50

Ley AC, Mauzerall D (1982) Absolute absorption cross-sections for photosystem II and the minumum quantum requirement for photosynthesis in Chlorella vulgaris. Biochim Biophys Acta 680:95-106

MacCaull WA, Platt T (1975) Diel variations in the photosynthetic parameters of coastal marne phytoplankton. Limnol Oceanogr 22:723-731

Mauzerall D (1972) Light-induced changes in Chlorella, and the primary photoreaction for the production of oxygen Proc Natl Acad Sci 69:1358-1362

Neale PJ, Marra J (1985) Short-term variations of $P_{\max }$ under natural irradiance conditions: a model and its implications

This article was submitted to the editor
Mar Ecol Prog Ser 26:113-124

Olaızola M, Geider RJ, Harrison WG, Graziano LM, Ferrari GM, Schlittenhardt PM (1996) Synoptic study of variations in the fluorescence-based maximum quantum efficiency of photosynthesis across the North Atlantic Ocean. Limnol Oceanogr 41:755-765

Parsons TR, Maita Y, Lalli CM (1984) A manual of chemical and biological methods for seawater analysis. Pergamon Press, Oxford

Petersen BJ (1980) Aquatic primary productivity and the ${ }^{14} \mathrm{C}$ $\mathrm{CO}_{2}$ method: a history of the productivity problem. Annu Rev Ecol Syst 11:359-385

Platt T, Sathyendranath S (1993) Estimators of primary production for interpretation of remotely sensed data on ocean color. J Geophys Res 98:14561-14576

Prezelin BB, Matlick HA (1980) Time-course of photoadaptation in the photosynthesis-irradiance relationship of a dinoflagellate exhibiting photosynthetic periodicity. Mar Biol 58:85-96

Prezelin BB, Sweeney BM (1977) Characterization of photosynthetic rhythms in marine dinoflagellates. II. Photosynthesis-irradiance curves and in vivo chlorophyll a fluorescence. Plant Physiol 60:388-392

Putt M, Prezelin BB (1985) Observations of diel patterns of photosynthesis in cyanobacteria and nanoplankton during 'el Niño'. J Plankton Res 10:373-383

Sakshaug $E$, Holm-Hansen $O$ (1986) Photoadaptation in Antarctic phytoplankton: variations in growth rate, chemical composition and $P$ versus $I$ curves. J Plankton Res 8 : $459-473$

Sathyendranath S, Longhurst A, Caverhill C, Platt P (1995) Regionally and seasonally differentated primary production in the North Atlantic. Deep Sea Res I 42:1773-1802

Smith EL (1936) Photosynthesis in relation to light and carbon dioxide. Proc Natl Acad Sci 22:504-511

Williams PJleB (1993) Chemical and tracer methods of measuring production. In: Li WKW (ed) ICES Mar Sci Symp, $197: 20-36$

Manuscript first received: November 27, 1995

Revised version accepted: December 10, 1996 